\title{
Astragalus-containing Chinese herbal combinations for advanced non-small-cell lung cancer: a meta-analysis of 65 clinical trials enrolling 475 I patients
}

This article was published in the following Dove Press journal:

Lung Cancer:Targets and Therapy

8 July 2010

Number of times this article has been viewed

Jean Jacques Dugoua'

Ping $\mathrm{Wu}^{2}$

Dugald Seely ${ }^{3}$

Oghenowede Eyawo ${ }^{4}$

Edward Mills ${ }^{4,5}$

'Graduate Department of Pharmaceutical Sciences, Leslie Dan Faculty of Pharmacy, University of Toronto, Toronto, Canada; ${ }^{2}$ Shanghai Hospital \#4, Shanghai, China;

${ }^{3}$ Department of Clinical Epidemiology, Canadian College of Naturopathic

Medicine, ${ }^{4}$ Faculty of Health Sciences, Simon Fraser University, Burnaby,

Canada; ${ }^{5}$ Faculty of Health Sciences,

University of Ottawa, Ottawa, Canada

Correspondence: Edward Mills

3I I-674 Leg in Boot Square,Vancouver,

BC,V5Z4B4, Canada

Email emills@cfenet.ubc.ca
Background: Non-small-cell lung cancer (NSCLC) is a leading cause of death. Interventions to reduce mortality in patients with NSCLC represent a patient-important field of research. Little is known about interventions used outside the Western world for NSCLC. One intervention widely used in Asia is astragalus-based herbal preparations.

Methods: We conducted a comprehensive systematic review of all published randomized clinical trials (RCTs) evaluating astragalus-based herbal preparations in NSCLC patients. We searched independently, in duplicate, 6 English language electronic databases and 2 Chineselanguage databases. We abstracted data independently, in duplicate on studies reporting of methods, survival outcomes, tumor responses, and performance score responses. We applied a random-effects meta-analysis and report outcomes as relative risks (RR) with $95 \%$ confidence intervals (CIs).

Results: We included 65 RCTs enrolling 4751 patients. All trials included the herbal preparations plus platinum-based chemotherapy versus chemotherapy alone. We pooled 7 studies $(n=529)$ reporting on survival at 6 months and found a pooled RR of 0.54 (95\% CI, 0.45 to 0.65 , $P \leq 0.0001)$. We included 20 trials $(\mathrm{n}=1520)$ on survival at 12 months and found a pooled RR of 0.65 (95\% CI, 0.54 to $0.79, P \leq 0.0001)$. This effect was consistent at 24 and 36 months. When we applied a composite endpoint of any tumor treatment response, we pooled data from 57 trials and found a pooled RR of 1.35 in favor of herbal treatment (95\% CI, 1.26 to 1.44 , $P \leq 0.0001)$. Statistical heterogeneity was low across trials.

Limitations: The quality of reporting the RCTs was generally poor. There is also reason to believe that studies reported as randomized may not be.

Conclusions: We found a large treatment effect of adding astragalus-based herbal treatment to standard chemotherapy regimens. There is a pressing need for validation of these findings in well-conducted RCTs in a Western setting.

Keywords: astralagus, non-small-cell lung cancer, herbal preparations

\section{Introduction}

Lung cancer is the leading cause of cancer death worldwide. ${ }^{1,2}$ In the United States, lung cancer is the leading cause of death, where it is estimated that 219,440 new cases of lung and bronchus cancer will be diagnosed in 2009; leading to 159,390 lung cancer-related deaths. ${ }^{3}$ Only $15 \%$ of all lung cancer patients are alive 5 years or more after diagnosis. ${ }^{3}$

The World Health Organization divides lung cancer into 2 major classes: nonsmall-cell lung cancer (NSCLC) and small-cell lung cancer (SCLC). NSCLC accounts 
for over $85 \%$ of all lung cancer cases, and it includes 2 major types: (1) non-squamous carcinoma (including adenocarcinoma, large-cell carcinoma, other cell types) and (2) squamous cell (epidermoid) carcinoma. ${ }^{4}$

The clinical guidelines for patients with NSCLC include combinations of cytotoxic chemotherapy and targeted biologic therapies, such as bevacizumab and erlotinib. ${ }^{4}$ Unfortunately, these current treatments involve non-specific, non-selective cytotoxic chemotherapy, which results in only a modest increase in survival and causes significant toxicity to the patient. ${ }^{5}$ According to a meta-analysis of 33 Phase III randomized controlled trials (RCTs), platinum-based chemotherapy offers symptomatic relief and modest improvements in survival (rarely $>2$ months). ${ }^{6}$ Data from 3 RCTs showed that platinum-based chemotherapy provided a median survival time of approximately 7 to 10 months. $^{7-9}$

In China, traditional Chinese medicines (TCM), which are herbal and/or animal/insect-based combinations, are frequently combined with chemotherapy for the treatment of cancer. ${ }^{10}$ One commonly used herbal compound, astragalus, appears to have a number of immunomodulatory properties. ${ }^{11-13}$ Astragalus appears to have antitumor activity where its potentiates LAK cell activity in vitro when used in combination with IL-2 ${ }^{14}$. Astragalus appears to restore in vitro T-cell function, which is suppressed in cancer patients. ${ }^{15}$ A meta-analysis of 34 RCTs found that Chinese medicines containing the herb astragalus (Astragalus membranaceus) may increase effectiveness of platinum-based chemotherapy when combined with chemotherapy. ${ }^{16}$ When compared to chemotherapy alone, astragalus-based Chinese medicines reduced risk of death at 12 months (risk ratio $[\mathrm{RR}]=0.67$; $95 \%$ confidence interval [CI], 0.52 to 0.87 ), improved tumor response data $(\mathrm{RR}=1.34 ; 95 \% \mathrm{CI}, 1.24$ to 1.46$)$, reduced risk of death at 24 months $(\mathrm{RR}=0.58 ; 95 \% \mathrm{CI}, 0.49$ to 0.68$)$, increased tumor response $(\mathrm{RR}=1.76 ; 95 \% \mathrm{CI}, 1.23$ to 2.53$)$ and stabilized or improved Karnofsky performance status $(\mathrm{RR}=1.28 ; 95 \%$ confidence interval [CI], 1.12 to 1.46$) .{ }^{16}$

There are a large number of published RCTs on astragalus-based Chinese medicines combined with platinum-based chemotherapy. ${ }^{16}$ Although a meta-analysis was conducted on NSCLC treatments using astragalus-based Chinese medicines along with platinum-based chemotherapy, ${ }^{16}$ this study did not included Chinese language studies in its search strategy. In a previous meta-analysis on TCM treatments for hepatocellular carcinoma, 44/45 RCTs extracted were in Chinese compared to 1/45 RCTs in English; thereby illustrating the importance of including Chinese manuscripts in the analysis. ${ }^{10}$
Our objective is to systematically review the scientific literature for RCTs on astragalus-based Chinese medicines combined with platinum-based chemotherapy and to meta-analyze the pooled data from these RCTs. Should the results be favorable, astragalus-chemotherapy combination treatment may provide an important step forward for new interventions for patients with NSCLC.

\section{Methods}

\section{Study inclusion criteria}

We included any study that randomized patients with advanced NSCLC, provided the treatment group with Chinese herbal medicines containing the herb astragalus in combination with standard platinum-based chemotherapy, provided the control group with platinum-based chemotherapy alone, and reported data on at least one of our outcomes of interest (survival, tumor response, or performance status) with sufficient detail to permit calculation of the risk ratios of each outcome. We excluded pharmacokinetic studies and non-randomized trials. We excluded studies that reported only laboratory values rather than clinical responses. We also excluded direct comparisons of TCM formulations.

\section{Search strategy}

PW and EM worked independently, in duplicate, searching the following English electronic databases: MEDLINE (1966 to June 2009), AMED (1985 to June 2009), Alt Health Watch (1995 to June 2009), CINAHL (1982 to June 2009), Nursing and Allied Health Collection: Basic (1985 to June 2009), Cochrane Database of Systematic Reviews (2008). In addition, PW and YL, both fluent in Mandarin and Cantonese, searched the Chinese databases CNKI (1979 to June 2009) and Wan Fang (1994 to June 2009) independently. No language restrictions were placed on the searches.

Three reviewers (PW, EM and YL) assessed eligibility based on the full text papers and conducted data extraction, independently, using a standard pre-piloted form. Disagreements were resolved by consensus or by a third reviewer. If the required information was not available in the published article, we obtained additional information in correspondence with the authors. We included all evaluated outcome measures including: survival at 6, 12, 24, and 36 months, disease stage, Karnofsky performace (KP), and the response evaluation criteria in solid tumors (RECIST). The response is categorized as complete response (CR), partial response (PR) outcomes, stable disease (SD), progressive disease (PD) and as $\mathrm{CR}+\mathrm{PR}$ as a composite for response rate. 
In addition, we extracted data on trial quality, protocol, and outcomes assessed. We assessed quality through the reporting of the following criteria: sequence generation and allocation concealment. We also noted the language in which the paper was written and the setting the studies were conducted. These criteria were not used for weighting covariates in the meta-analysis; instead, these were considered a priori explanations for study heterogeneity.
All inclusion and exclusion criteria and the categorization of outcomes were made before any meta-analysis of the data. Our decision to group together for this meta-analysis those studies using platinum-based chemotherapy was based on the fact that this therapy is currently a standard treatment for advanced NSCLC. Following the example set by D'Addario et $\mathrm{a}^{17}$ and the Cochrane Collaboration's Non-Small-Cell Lung Cancer Collaborative Group, ${ }^{18}$ platinum-based

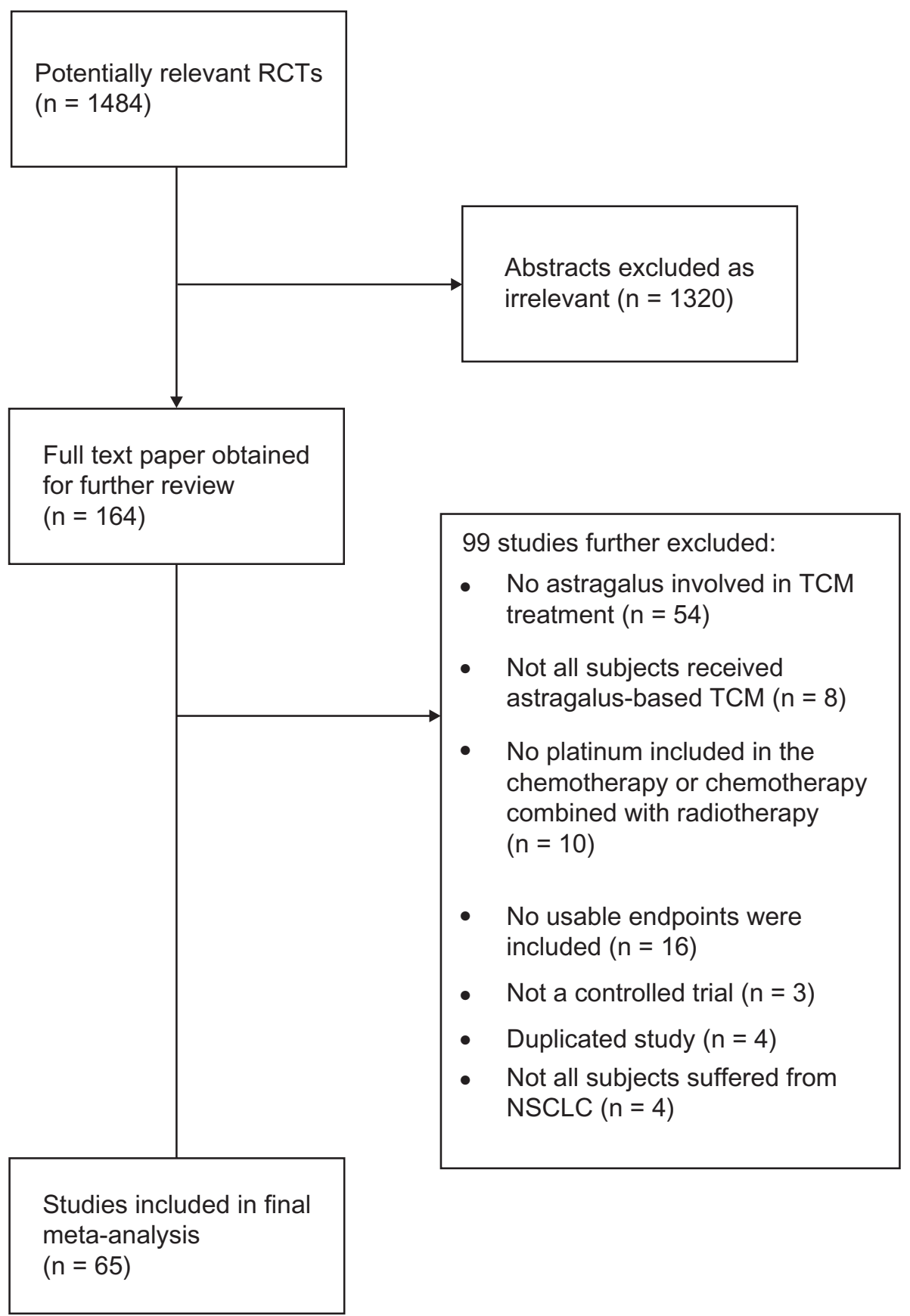

Figure I Flow diagram of included studies. 
chemotherapy was grouped together as a therapeutic class when assessing efficacy of treatment for NSCLC. Each stage of the planning, design, analysis, and reporting of this metaanalysis was conducted in accordance with the QUOROM Statement guidelines. ${ }^{19}$

\section{Analysis of outcomes}

Survival

Given that all of the studies identified in our systematic search reported crude survival data as the number of patients in each treatment group who died by $6,12,24$, or 36 months, we calculated the probability of failure (death) as the number of patients who had died by each time point divided by the total number of patients enrolled at the start of the trial for each treatment group. This approach is intentionally conservative: if some patients dropped out of the study, retaining them in the denominator as we have done would lower the estimate of effectiveness. This is analogous to an intention-to-treat analysis. ${ }^{20}$ The risk ratios of treatment failure (death) at each time point was calculated as the proportion who died in the astragalus-based herbal medicine plus platinum-based chemotherapy treatment group, compared to the proportion in the platinum-based chemotherapy group. Thus, RR less than 1 favors the combination regimen.

\section{Objective tumor response}

Given that most of the studies identified in our systematic search reported tumor response at conclusion of treatment using RECIST, ${ }^{21}$ we calculated the probability of tumor response as the number of patients experiencing any response (complete response plus partial response) divided by the total number of patients in each treatment group (complete response plus partial response plus no change plus progressive disease). The RR of tumor response was calculated as the probability of tumor response in the astragalusbased herbal medicine plus platinum-based chemotherapy treatment group, divided by this proportion in the platinumbased chemotherapy group. Thus, RR more than 1 favors the combination regimen. This is the approach for meta-analysis of tumor response recommended by Sutton et al. ${ }^{22}$

\section{Performance status}

Many of the studies identified in our systematic search reported performance status using the Karnofsky performance scale, ${ }^{23}$ with most using a 10 -point change as the cutoff for improved or worse performance status, and a few others using a 20-point change as the cutoff. We therefore calculated the probability of improved or stable performance status as the proportion of improved or stable performance status: ( $>10$-point increase plus no change) divided by the total ( $>10$-point increase, plus no change, plus $>10$-point decrease). The RR of improved or stable performance status was calculated as the proportion of improved or stable performance status in the astragalus-based herbal medicine plus platinum-based chemotherapy treatment group, divided by this proportion in the platinum-based chemotherapy group. Thus, RR more than 1 favors the combination regimen.

\section{Analysis}

We used the random-effects model of DerSimonian and Laird $^{24}$ to estimate the summary RR for each of the four outcomes: risk of death (at 6, 12, 24, and 36 months), tumor response, performance status, and severe chemotherapy toxicity. We used the $\mathrm{I}^{2}$ statistic to assess between-study heterogeneity and interpreted the outcome as $<50 \%$ as nonproblematic heterogeneity. To assess publication bias, we used the Begg-Mazumdar test, which examines the association between the effect estimates of individual studies and their variances; significant correlation between these two factors identifies publication bias. ${ }^{25}$

We applied the RR and 95\% CI as our primary effect measure in this analysis. For analysis examining response, favorable results for the TCM intervention are in the direction greater than 1. In circumstances of zero outcome events in either arm of a trial, we used the Haldane method and added 1 to each arm, as suggested by Sheehe. ${ }^{26}$ We first pooled studies on all interventions versus all controls using the DerSimonian-Laird random effects method. ${ }^{27}$ This method recognizes and anchors studies as a sample of all potential studies, and incorporates an additional between-study component to the estimate of variability. We calculated the $\mathrm{I}^{2}$ statistic for each analysis as a measure of the proportion of the overall variation that is attributable to between-study heterogeneity. ${ }^{28}$ Forest plots are displayed for the primary analysis, showing individual study effect measures with 95\% CIs and the overall DerSimmonian-Laird pooled estimate. We conducted a meta-regression analysis using the unrestricted maximum likelihood method to determine if the a priori covariates of TCM formulation yielded differing effects. We examined publication bias visually and through the Begg-Mazumdar tests. We calculated the optimal information size (OIS) required to determine adequate power across trials. We used Stats Direct and Comprehensive Meta-Analysis (Version 2) for all statistical procedures. All $P$ values are 2-sided and a $P$ value $<0.05$ was considered significant. PW and EM conducted the analysis. 


\section{Results}

\section{Included studies}

Our systematic search identified 1484 potentially relevant abstracts, of which 164 were identified as requiring full-text article retrieval (Figure 1). Close screening of these 221 studies identified 65 studies that met our inclusion criteria, containing a total of 4751 patients. Most studies were small (median 67, interquartile range 56 to 83). Studies poorly reported methodological issues including sequence generation (25\%), allocation concealment (3\%), and reporting of adverse events $(67 \%)$. Table 1 provides the study characteristics.

\section{Survival}

We pooled 7 studies $^{29-35}(\mathrm{n}=529)$ reporting on survival at 6 months and found a pooled RR of 0.54 (95\% CI, 0.45 to $0.65, P \leq 0.0001, \mathrm{I}^{2}=0 \%, 95 \% \mathrm{CI}, 0 \%$ to $58 \%, P=0.74$, see Figure 2). We included 20 trials $^{30-49}(\mathrm{n}=1520)$ in our analysis of survival at 12 months and found a pooled RR of 0.65 (95\% CI, 0.54 to $0.79, P \leq 0.0001, \mathrm{I}^{2}=74 \%, 95 \%$ CI, $57 \%$ to $82 \%, P<0.0001$, see Figure 3 ). As $12-$ month survival was our primary outcome, we applied the publication bias assessment and found no evidence of publication bias (Kendall's tau $=-0.157, P=0.31$ ). We included 13 trials $^{32,34,35,40-49}(\mathrm{n}=1090)$ with survival rates reported at 24 months and found a pooled RR of 0.74 (95\% CI, 0.66 to $0.84, P \leq 0.0001, \mathrm{I}^{2}=64 \%, 23 \%$ to $78 \%, P=0.0008$, see Figure 4). We included data from 10 trials $^{35,40-46,48,49}(\mathrm{n}=878)$ reporting on survival at 36 months and found a pooled RR of $0.86\left(95 \% \mathrm{CI}, 0.80-0.92, P \leq 0.0001, \mathrm{I}^{2}=29 \%, 95 \% \mathrm{CI}\right.$, $0 \%$ to $65 \%, P=0.17$, see Figure 5 ).

\section{Tumor response}

We were able to include data from 27 trials $^{37,39-43,50-70}(\mathrm{n}=1759)$ reporting on complete responses to treatment and found a pooled RR of 1.43 in the direction of favorable outcomes for herbal-based treatment ( $95 \%$ CI, 0.98 to $2.10, P=0.07, \mathrm{I}^{2}=0 \%$, $95 \% \mathrm{CI}, 0 \%$ to $42 \%, P \leq 0.99$ ). The same 27 trials reported on partial response to treatment and found a pooled RR of 1.35 favoring herbal treatment $(95 \% \mathrm{CI}, 1.19$ to $1.53, P \leq 0.0001$, $\mathrm{I}^{2}=0 \%, 95 \% \mathrm{CI}, 0 \%$ to $\left.38 \%, P=0.99\right)$. When we applied a composite endpoint of any treatment response we pooled data from 57 trials $^{30,32-35,37,39-45,48-50,87-90}$ and found a pooled RR of 1.35 in favor of herbal treatment $(95 \% \mathrm{CI}, 1.26$ to $1.44, P \leq 0.0001$, $\mathrm{I}^{2}=0 \%, 0 \%$ to $28 \%, P=0.99$, see Figure 6 ).

\section{Performance status}

We included data from 35 trials $^{35,37,43,48-53,55,56,58-64,66-72}$ $77,80,84,85,87,88,91-94(\mathrm{n}=2650)$ assessing stable or improved
Karnofsky scores and found a pooled RR of 1.58 (95\%, 1.39 to $1.81, P \leq 0.0001, \mathrm{I}^{2}=69 \%, 55 \%$ to $78 \%, P \leq 0.0001$, see Figure 7).

\section{Discussion}

Our findings should be of interest to cancer researchers and funding agencies. We found consistent evidence of improved survival and tumor response in astragalus-based herbal medicine therapy combined with platinum-based chemotherapy compared with platinum-based chemotherapy alone, the standard of care. While there is reason to be cautious of the quality of the included clinical trials, due to their small sample sizes and inadequate reporting of methodological issues, there has been a consistent direction of treatment effect that warrants further examination by experienced clinical trialists in a transparent manner.

Our study has both strengths and limitations to consider. Strengths include our extensive searching and identification of Chinese clinical trials that few systematic review groups may be able to accomplish. Our analysis used a broad approach that considered all astragalus containing herbal combinations as comparatively similar, thus allowing much greater power to detect an effect over a single trial. It is possible that specific combination exert a differing therapeutic effect; however we were unable to identify such specific formulations. The limitations of our study are predominantly related to the need for caution in interpreting the clinical trials. There is consistent evidence that publication bias may exist in Chinese medical journals and thus, only positive trials are published. ${ }^{95}$ Although we recognize favorable outcomes may be more likely to be published, our analysis actually does not find that only positive trials are published. If one examines the forest plots, on average, most trial are negative, but when pooled, become positive. A recent evaluation, by $\mathrm{Wu}$ et al, found that many studies labelled as RCTs with Chinese journals were, in fact, not randomized. ${ }^{96}$ In our own experience, we recognize many Chinese clinical trialists have not been exposed to appropriate clinical epidemiology training. Yet even if our analysis includes predominantly non-randomized studies, the consistency of therapeutic effect warrants further examination. Other systematic reviews of published studies from Chinese journals have identified specific journals with better study quality, and also found trends in improvement of study quality over time. ${ }^{97} \mathrm{We}$ assessed publication bias in our primary outcome (survival at 12 months) and did not find statistical evidence of bias, although funnel plots and statistical tests cannot identify the absence of publication bias. 


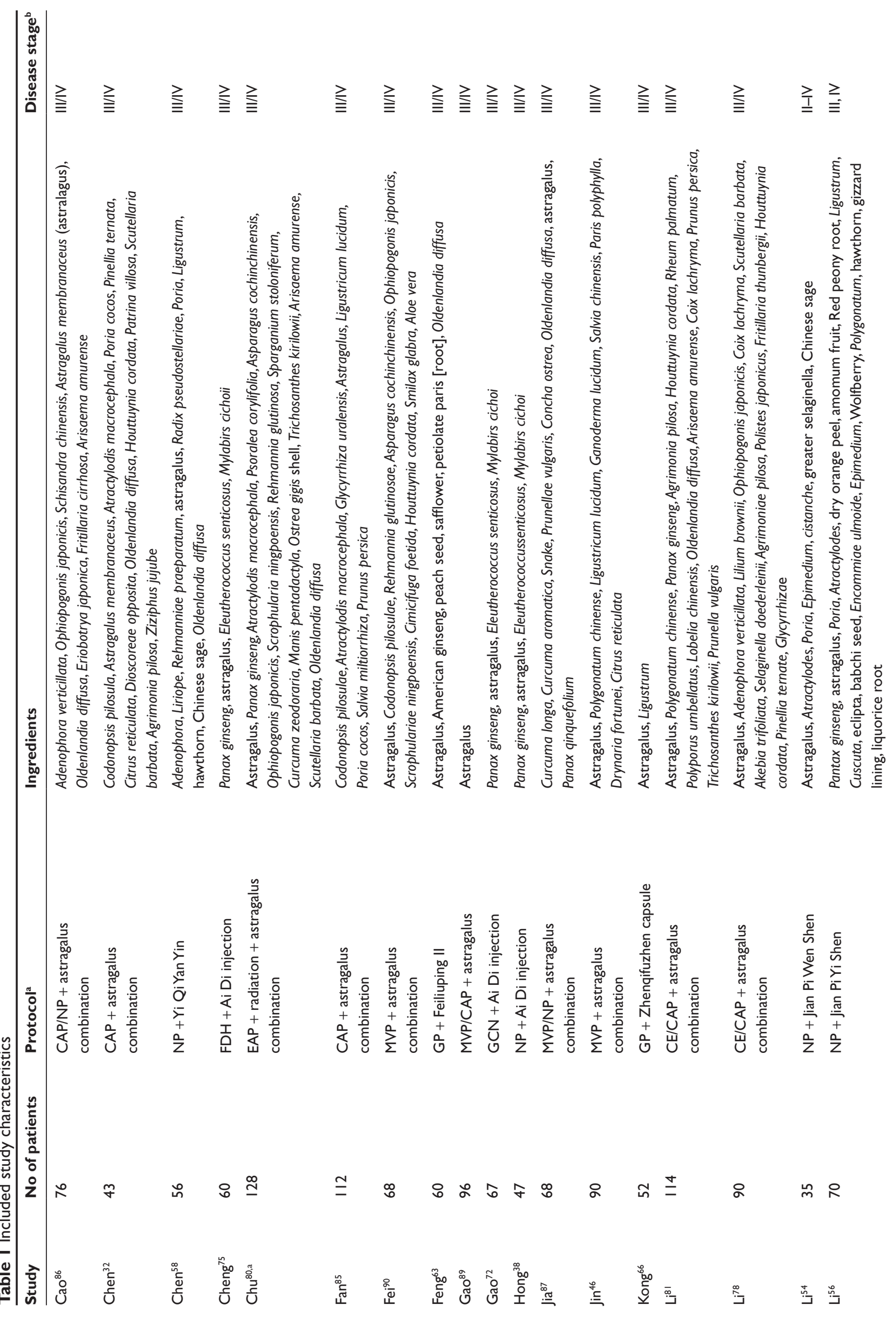




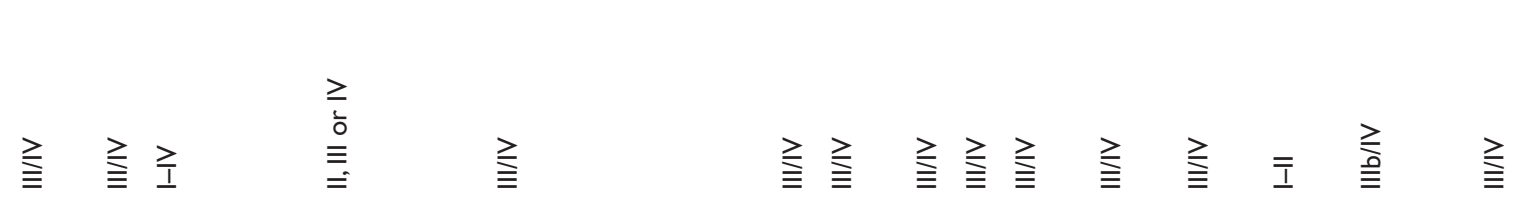
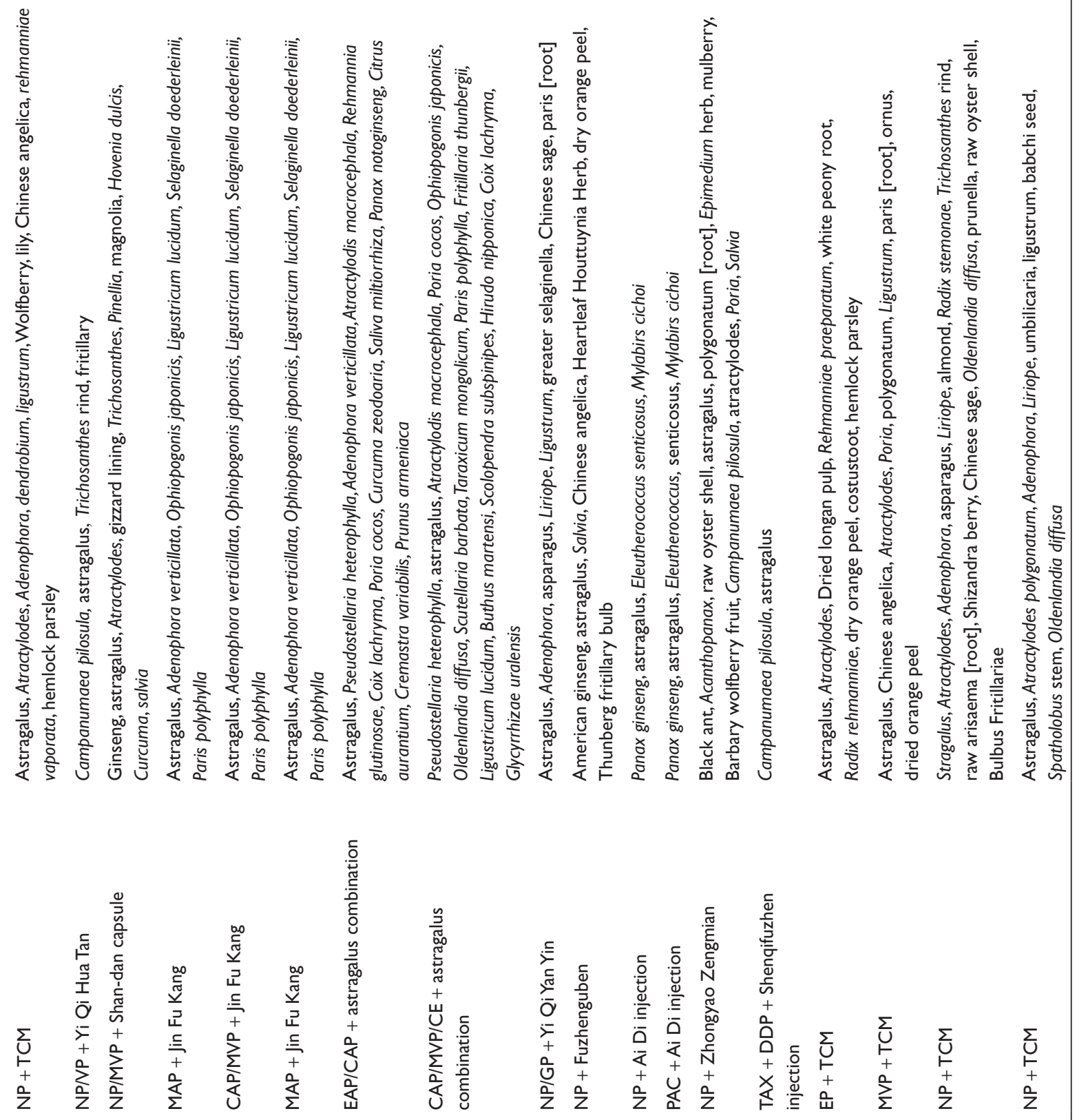

๓

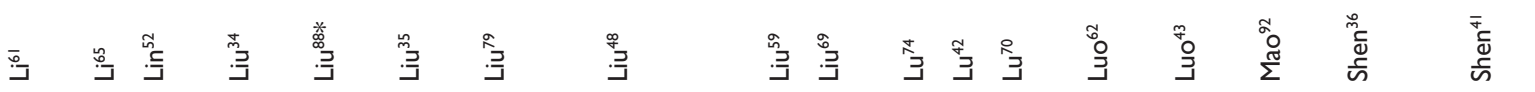




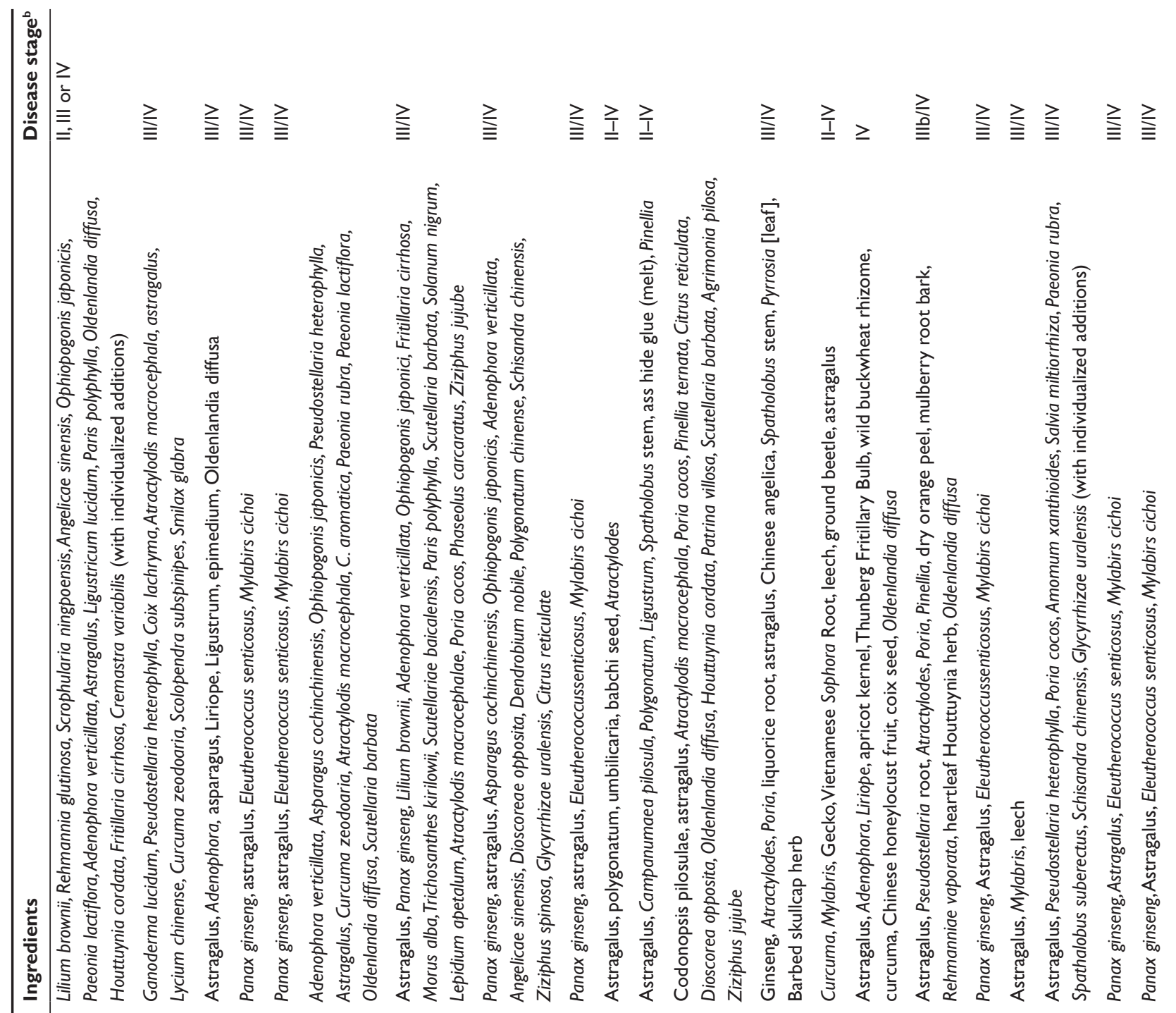

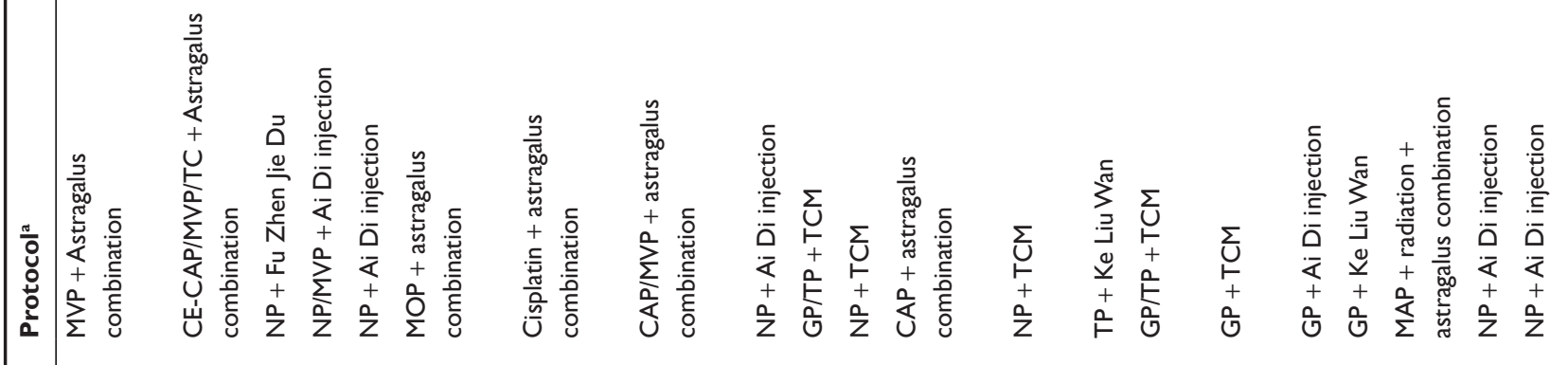

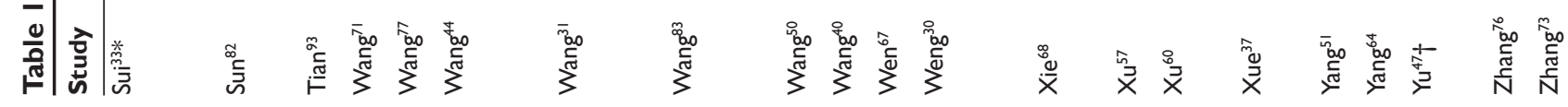




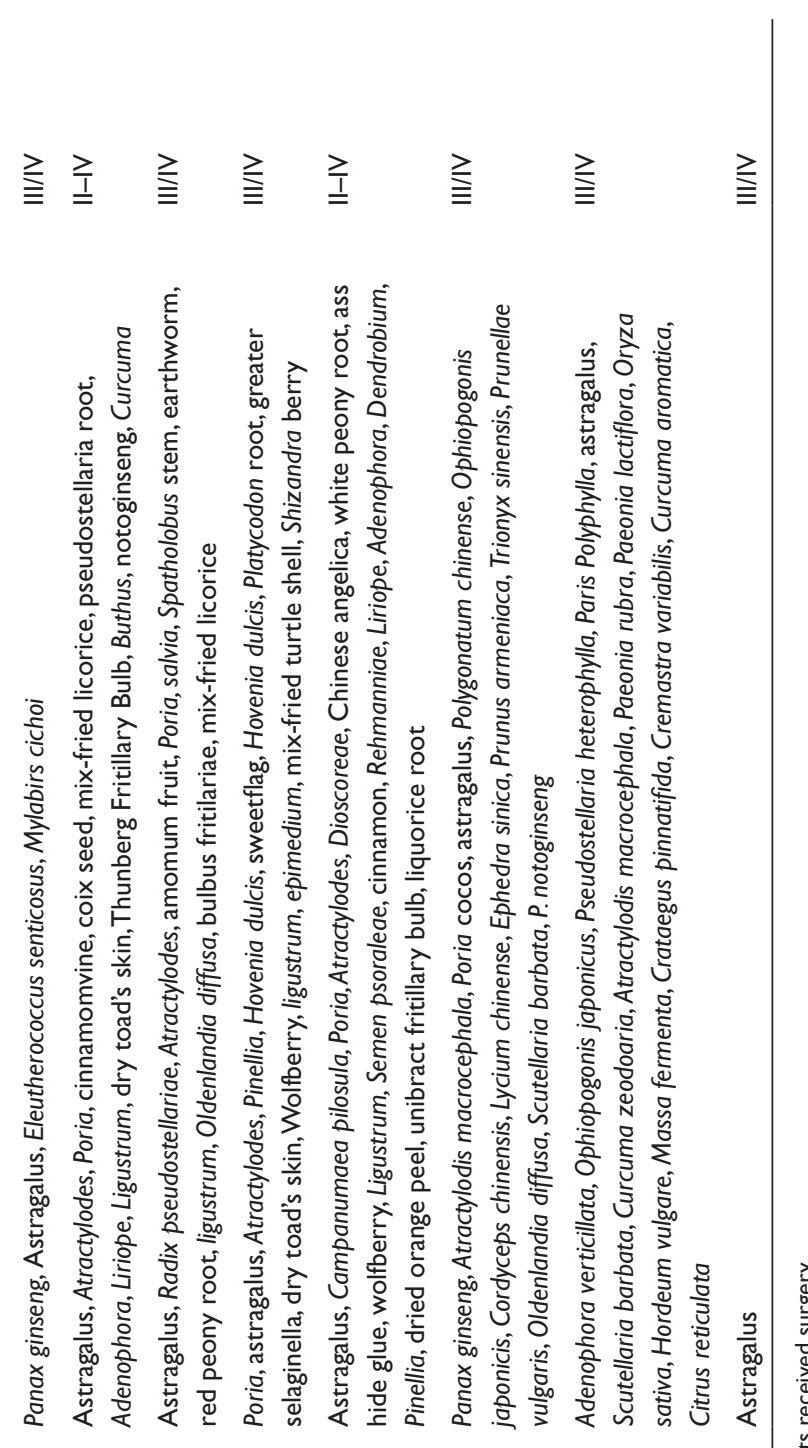

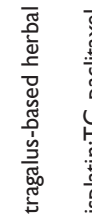

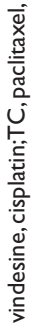

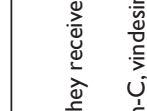

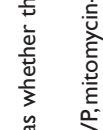

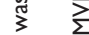

旁竞

官

势

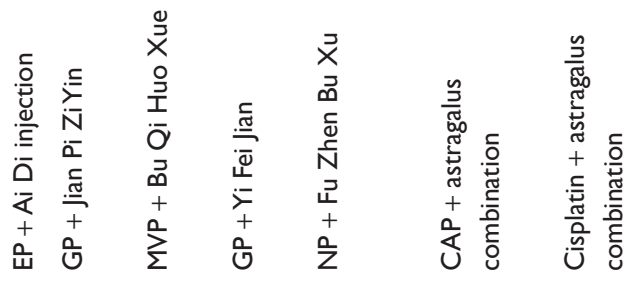

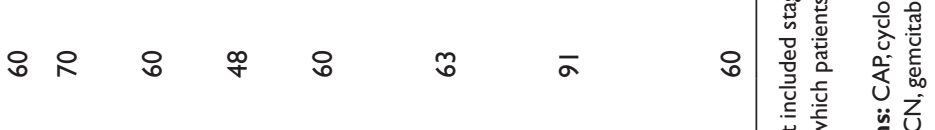

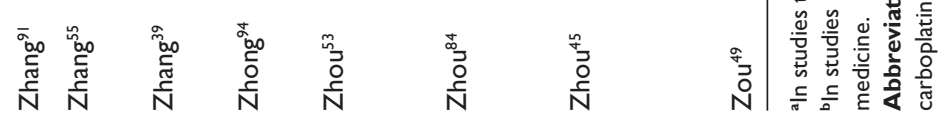




\section{Relative risk meta-analysis plot (random effects)}

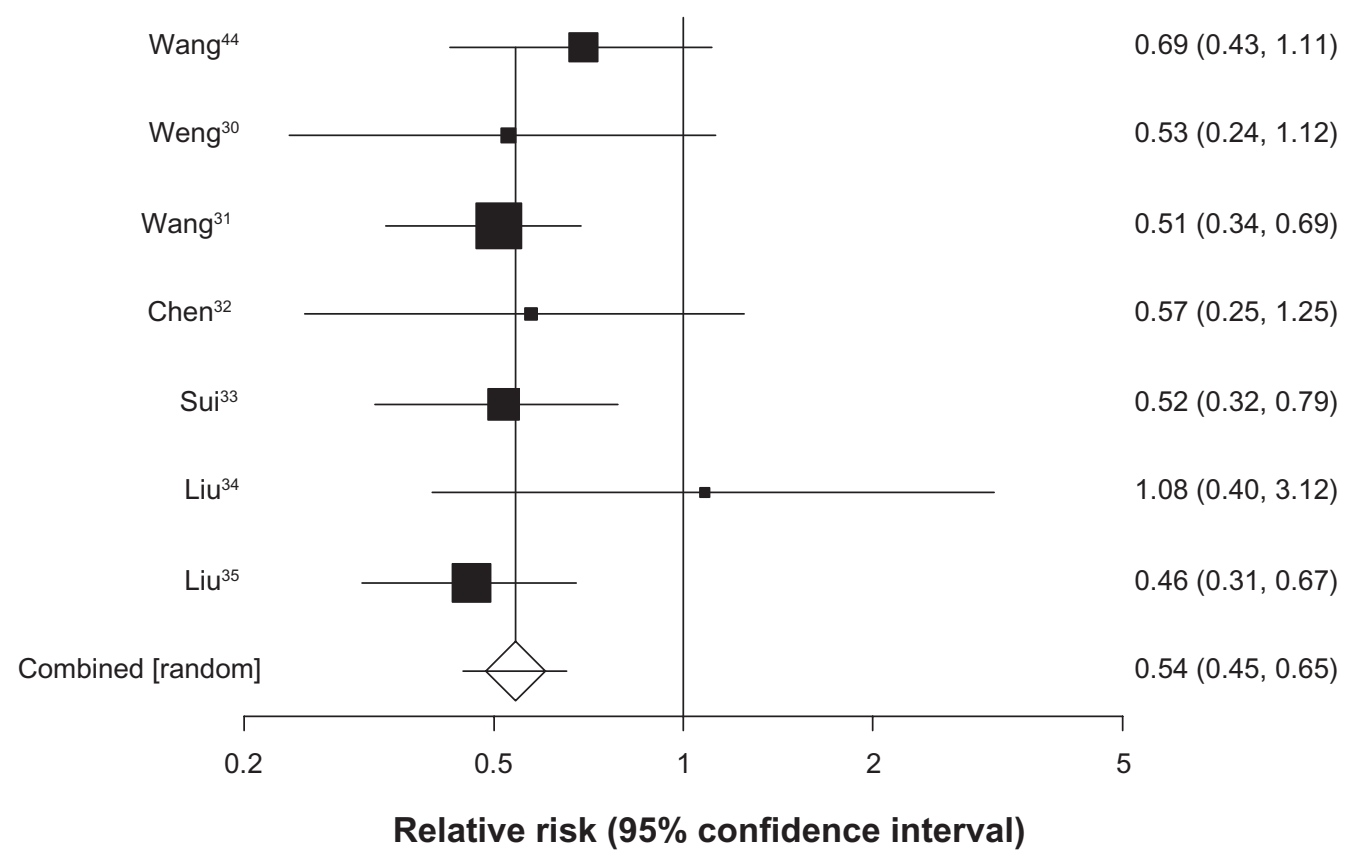

Figure 2 Six-month survival with astragalus-based herbs and platinum-based chemotherapy versus platinum-based chemotherapy alone.

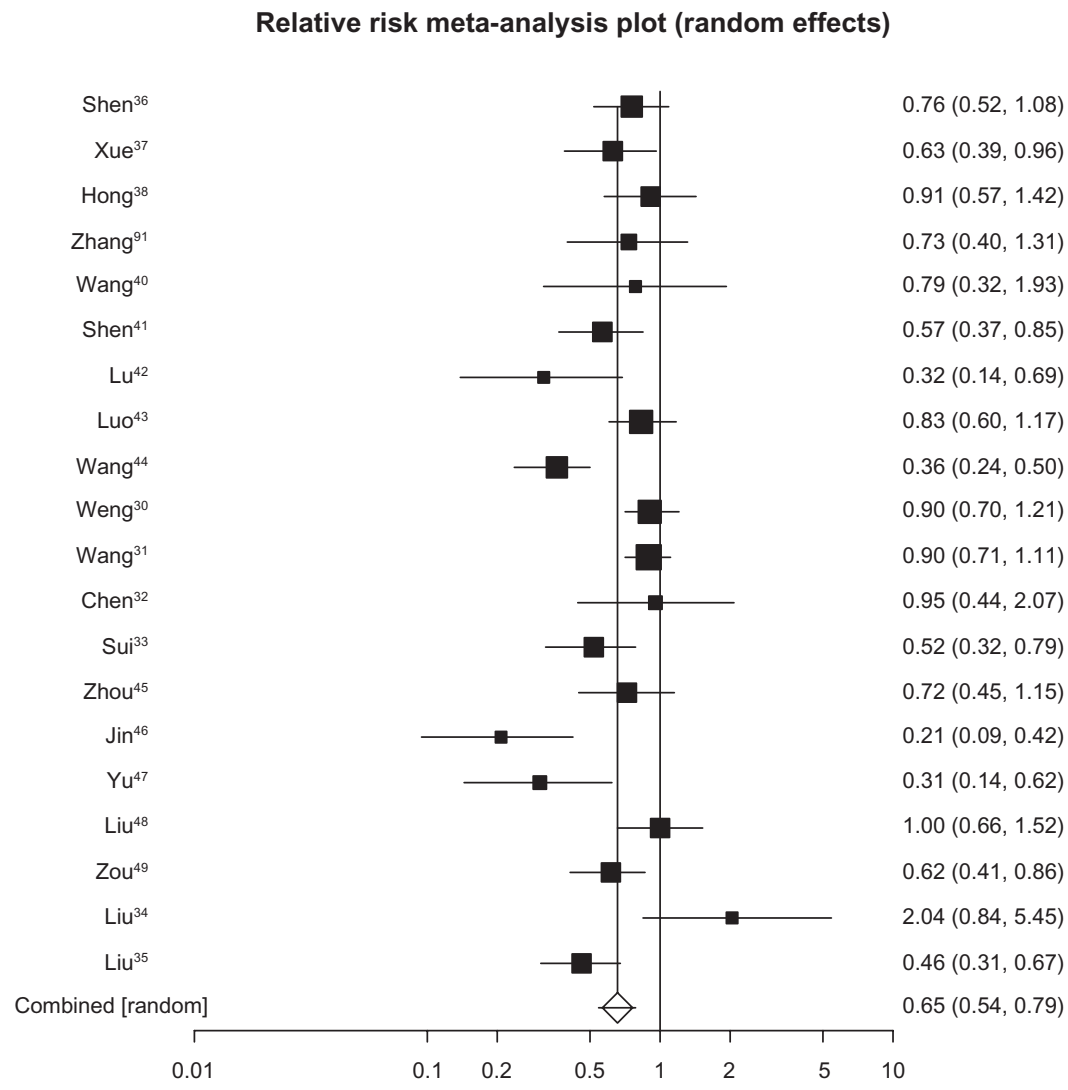

Relative risk (95\% confidence interval)

Figure 3 Twelve-month survival with astragalus-based herbs and platinum-based chemotherapy versus platinum-based chemotherapy alone. 


\section{Relative risk meta-analysis plot (random effects)}

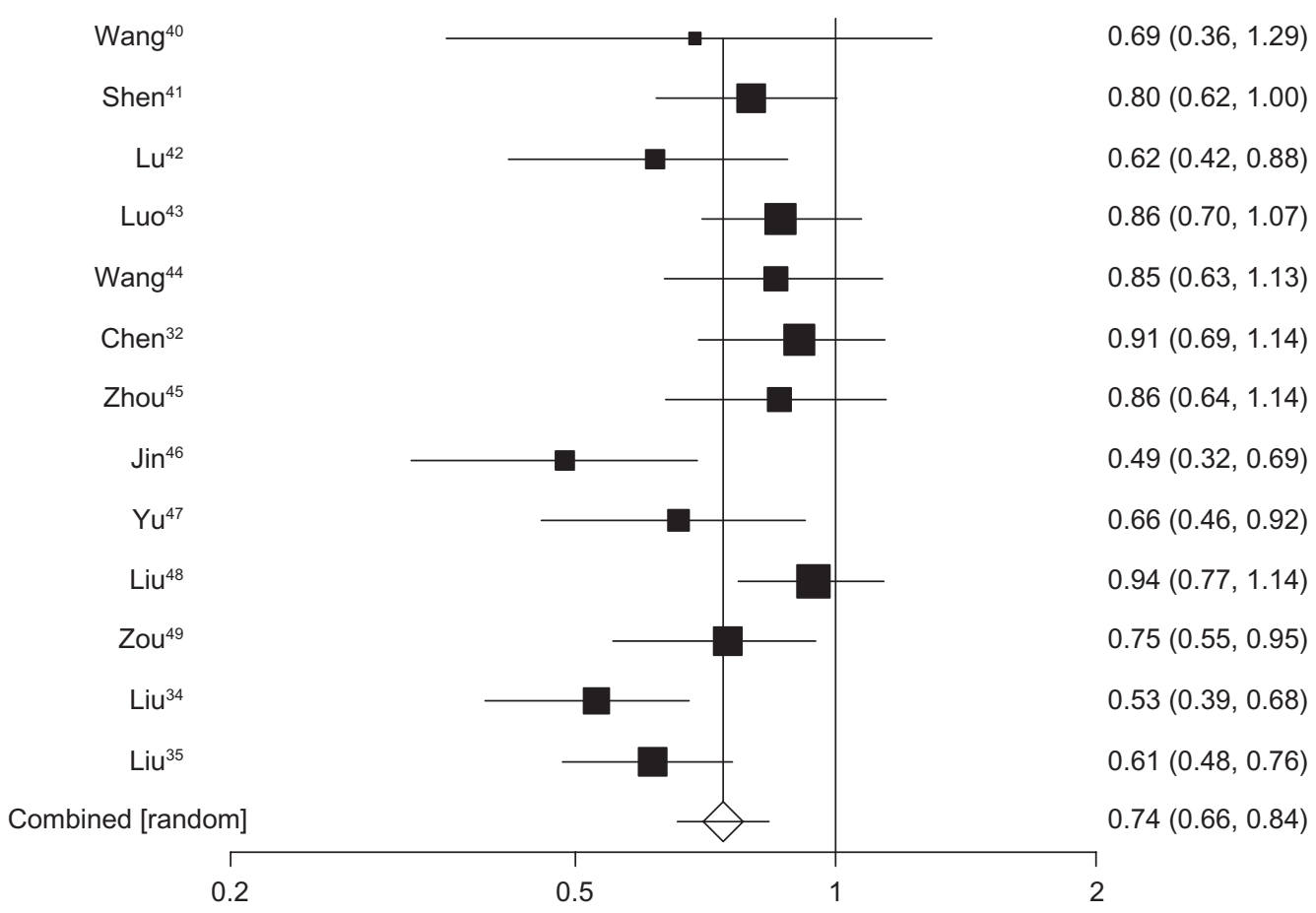

Relative risk $(95 \%$ confidence interval)

Figure 4 Twenty-four-month survival with astragalus-based herbs and platinum-based chemotherapy versus platinum-based chemotherapy alone.

\section{Relative risk meta-analysis plot (random effects)}

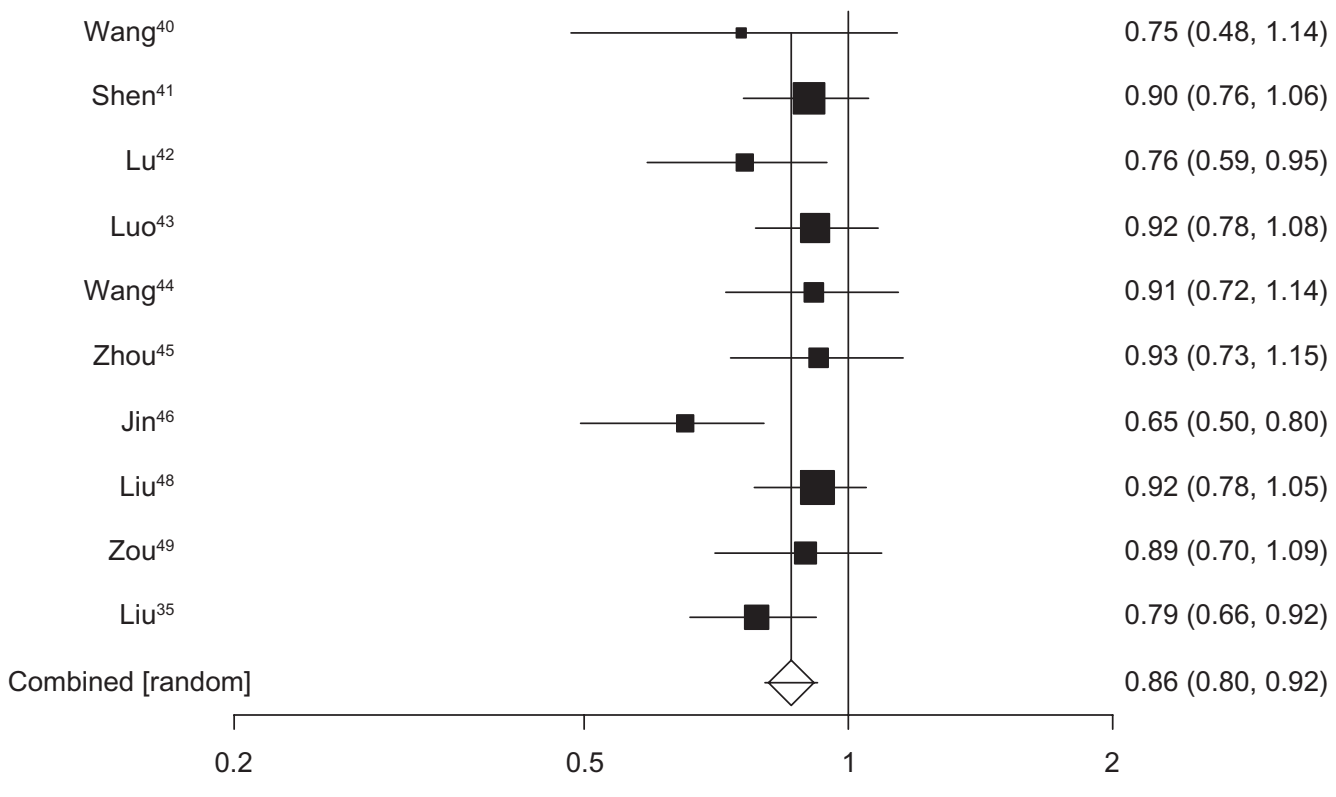

Relative risk ( $95 \%$ confidence interval)

Figure 5 Thirty-six-month survival with astragalus-based herbs and platinum-based chemotherapy versus platinum-based chemotherapy alone. 
Relative risk meta-analysis plot (random effects)

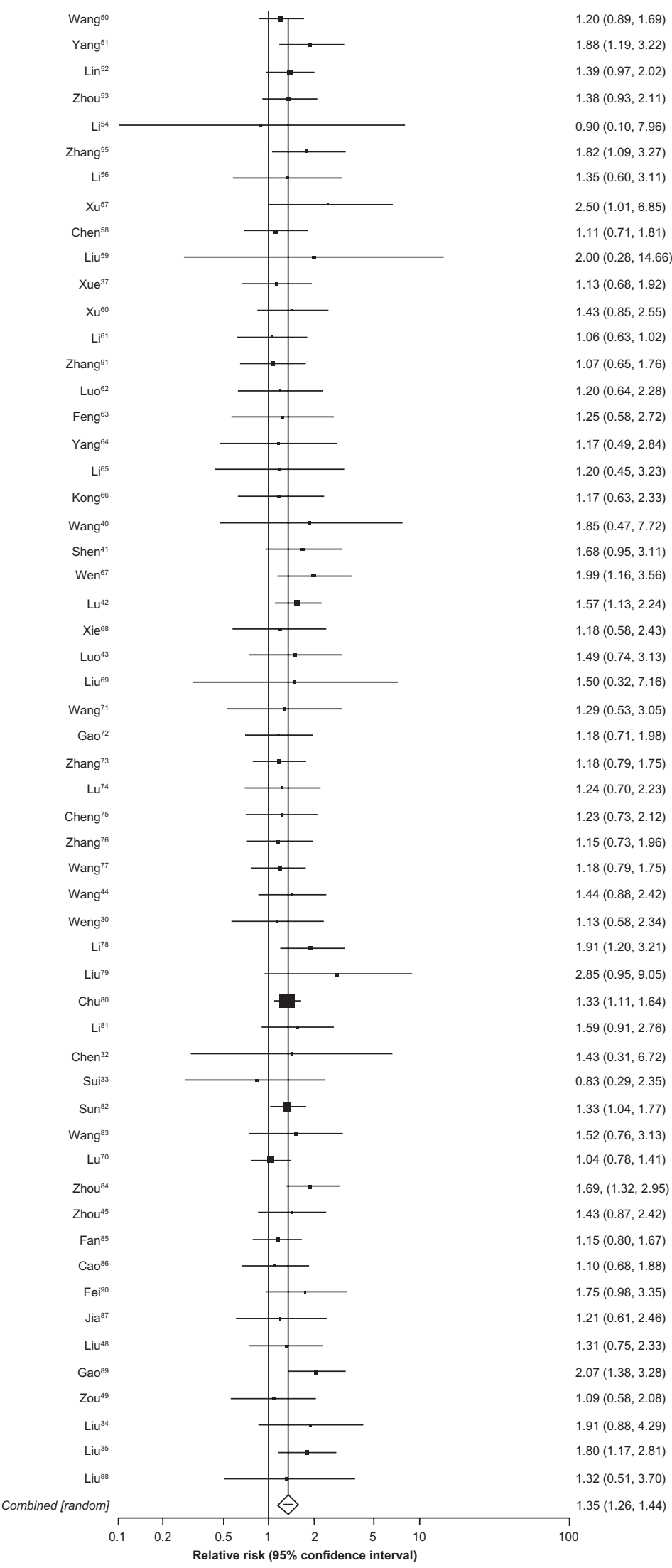

Figure 6 Tumor response with astragalus-based herbs and platinum-based chemotherapy versus platinum-based chemotherapy alone. 


\section{Relative risk meta-analysis plot (random effects)}

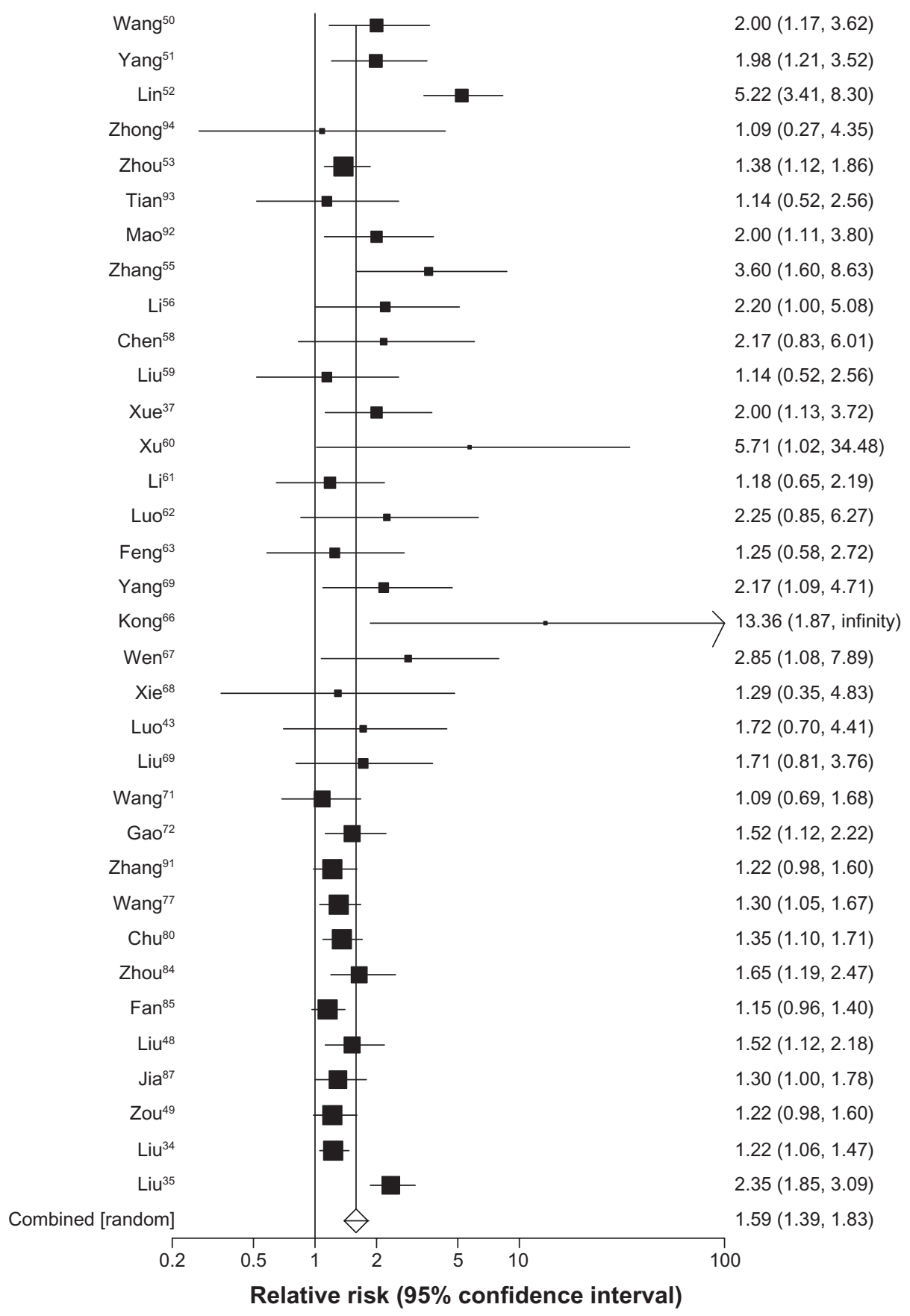

Figure 7 Stable/improved Karnofsky performance status with astragalus-based herbs and platinum-based chemotherapy versus platinum-based chemotherapy alone.

The reporting of quality features including how trials were randomized and how allocation concealment was achieved adds further caution to our study interpretation. While the inadequate reporting of these items is undesirable, there is, as yet, conflicting evidence that the reporting of these issues affects the magnitude of treatment effect. ${ }^{98-100}$

Given the consistency of treatment effect, large number of trials, importance of the disease and the caution about study quality it seems only reasonable that a clinical trial should be conducted in a Western setting that can ensure adequate sample size and concealed allocation to study arms. Such a clinical trial would provide strong inferences into the believability of our meta-analysis findings and could massively impact drug development. However, until a trial is conducted, we recommend counseling interested patients to maintain cautious optimism on any treatment effect and 
discuss with their oncology physician about potential costs and harms.

Our study builds on an existing collaboration between researchers in China and in North America. We recognize that important and effective drugs have been discovered by examining the Chinese medical literature for existing clinical trials. Artemisin-based therapy for malaria and oseltamivir $\left(\right.$ Tamiflu $^{\circledR}$ ) for influenza are two compelling examples. ${ }^{101,102}$ We have previously used this approach for examining potentially effective interventions for hepatocellular cancers and found evidence of existing interventions that have never been evaluated in the West, despite compelling evidence of effectiveness. We believe that this approach represents a low-cost approach to identifying potentially effective new opportunities for drug development.

Additional research is needed to further understand the specific immunologic and cytotoxic mechanisms that astragalus may affect as an adjunct to chemotherapy for the treatment of advanced NSCLC.

\section{Acknowledgments}

This study was generously supported by the Lotte and John Hecht Memorial Foundation. We thank Y Liang for searching assistance.

\section{Disclosure}

The authors declare no potential conflicts of interest.

\section{References}

1. Carney DN. Lung cancer - time to move on from chemotherapy. NEngl J Med. 2002;346:126-128.

2. Chute JP, Chen T, Feigal E, Simon R, Johnson BE. Twenty years of phase III trials for patients with extensive-stage small-cell lung cancer: perceptible progress. J Clin Oncol. 1999;17:1794-1801.

3. Horner MJ, Ries LAG, Krapcho M, et al. SEER Cancer Statistics Review, 1975-2006, National Cancer Institute. Bethesda, MD: National Cancer Institute; 2008.

4. NCCN. National Comprehensive Cancer Network (NCCN) - Clinical Practice Guidelines: Non-small Cell Lung Cancer v.2.: Available from http://www.nccn.org/professionals/physician_gls/PDF/nscl.pdf; 2009.

5. Burris HA 3rd. Shortcomings of current therapies for non-small-cell lung cancer: unmet medical needs. Oncogene. 2009;28 Suppl 1:S4-S13.

6. Breathnach OS, Freidlin B, Conley B, et al. Twenty-two years of phase III trials for patients with advanced non-small-cell lung cancer: sobering results. J Clin Oncol. 2001;19:1734-1742.

7. Kelly K, Crowley J, Bunn PA Jr, et al. Randomized phase III trial of paclitaxel plus carboplatin versus vinorelbine plus cisplatin in the treatment of patients with advanced non-small-cell lung cancer: a Southwest Oncology Group trial. J Clin Oncol. 2001;19: 3210-3218.

8. Scagliotti GV, Parikh P, von Pawel J, et al. Phase III study comparing cisplatin plus gemcitabine with cisplatin plus pemetrexed in chemotherapynaive patients with advanced-stage non-small-cell lung cancer. $J$ Clin Oncol. 2008;26:3543-3551.
9. Schiller JH, Harrington D, Belani CP, et al. Comparison of four chemotherapy regimens for advanced non-small-cell lung cancer. $N$ Engl $J$ Med. 2002;346:92-98.

10. Wu P, Dugoua JJ, Eyawo O, Mills EJ. Traditional Chinese Medicines in the treatment of hepatocellular cancers: a systematic review and meta-analysis. J Exp Clin Cancer Res. 2009;28:112.

11. Chu DT, Wong WL, Mavligit GM. Immunotherapy with Chinese medicinal herbs. II. Reversal of cyclophosphamide-induced immune suppression by administration of fractionated Astragalus membranaceus in vivo. J Clin Lab Immunol. 1988;25:125-129.

12. Shao BM, Xu W, Dai H, Tu P, Li Z, Gao XM. A study on the immune receptors for polysaccharides from the roots of Astragalus membranaceus, a Chinese medicinal herb. Biochem Biophys Res Commun. 2004;320:1103-1111.

13. Sun Y, Hersh EM, Lee SL, McLaughlin M, Loo TL, Mavligit GM. Preliminary observations on the effects of the Chinese medicinal herbs Astragalus membranaceus and Ligustrum lucidum on lymphocyte blastogenic responses. J Biol Response Mod. 1983;2:227-237.

14. Chu DT, Lepe-Zuniga J, Wong WL, LaPushin R, Mavligit GM. Fractionated extract of Astragalus membranaceus, a Chinese medicinal herb, potentiates LAK cell cytotoxicity generated by a low dose of recombinant interleukin-2. J Clin Lab Immunol. 1988;26:183-187.

15. Chu DT, Wong WL, Mavligit GM. Immunotherapy with Chinese medicinal herbs. I. Immune restoration of local xenogeneic graftversus-host reaction in cancer patients by fractionated Astragalus membranaceus in vitro. J Clin Lab Immunol. 1988;25:119-123.

16. McCulloch M, See C, Shu XJ, et al. Astragalus-based Chinese herbs and platinum-based chemotherapy for advanced non-small-cell lung cancer: meta-analysis of randomized trials. J Clin Oncol. 2006;24:419-430.

17. D'Addario G, Pintilie M, Leighl NB, Feld R, Cerny T, Shepherd FA. Platinum-based versus non-platinum-based chemotherapy in advanced non-small-cell lung cancer: a meta-analysis of the published literature J Clin Oncol. 2005;23:2926-2936.

18. Non-Small Cell Lung Cancer Collaborative Group. Chemotherapy for non-small cell lung cancer. Cochrane Database System Review. 2004: CD002139.

19. Moher D, Cook DJ, Eastwood S, Olkin I, Rennie D, Stroup DF. Improving the quality of reports of meta-analyses of randomised controlled trials: the QUOROM statement. Quality of Reporting of Meta-analyses. Lancet. 1999;354:1896-1900.

20. Heritier SR, Gebski VJ, Keech AC. Inclusion of patients in clinical trial analysis: the intention-to-treat principle. Med J Aust. 2003; 179:438-440.

21. World Health Organization (WHO). WHO Handbook for Reporting Results of Cancer Treatment. Geneva, Switzerland: World Health Orgnaization; 1979.

22. Sutton AJ, Abrams KR, Jones DR, Sheldon TA, Song F. Methods for Meta-Analysis in Medical Research. Chichester, United Kingdom: John Wiley \& Sons; 2000.

23. Yates JW, Chalmer B, McKegney FP. Evaluation of patients with advanced cancer using the Karnofsky performance status. Cancer. 1980;45:2220-2224.

24. DerSimonian R, Laird N. Meta-analysis in clinical trials. Control Clin Trials. 1986;7:177-188.

25. Begg CB, Mazumdar M. Operating characteristics of a rank correlation test for publication bias. Biometrics. 1994;50:1088-1101.

26. Sheehe PR. Combination of log relative risk in retrospective studies of disease. Am J Public Health Nations Health. 1966;56:1745-1750.

27. Fleiss JL. The statistical basis of meta-analysis. Stat Methods Med Res. 1993;2:121-145.

28. Higgins JP, Thompson SG. Quantifying heterogeneity in a meta-analysis. Stat Med. 2002;21:1539-1558.

29. Wang JX, Zhu CL. A clinical observation of the effect of supplementing Qi and nourishing yin prescription combined with MOP on the stage III IV of the nonsmall cell lung cancer. Shi Yong Zhong Xi Yi Jie He Za Zhi. 1997;10:1839-1840. 
30. Weng JY. Chinese and Western medicine in the treatment of 19 cases of advanced nonsmall cell lung cancer. Zhejiang Zhong Liu. 1998;4:129.

31. Wang YQ. Integrated Chinese and Western medicine combined treatment for primary-stage lung cancer with pleural effusion. Liaoning Zhongyi Zazhi. 2000;27:129.

32. Chen GP, Weng JY. Treatment value of Chinese medicine combined with chemotherapy for excision of lung cancer. Zhejiang Zhong $X i Y_{i}$ Jie He Za Zhi. 2000;10:407-408.

33. Sui DJ, Zhou LN, Li G. Fuzhengjian to treat middle to late-stage lung cancer in 40 patients. Shanxi Zhongyi. 2001;17:16-17.

34. Liu JX, Shi ZM, Xu ZH, et al. Clinical observations of Jin Fu Kang Kou Fu Ye in treating non-small-cell lung cancer. Zhong Yi Za Zhi. 1997;38:727-729.

35. Liu JX, Shi ZM, Li HG, et al. Clinical observations of lung nourishing anti-tumor beverage in treating non-small-cell lung cancer in 271 cases. Shanghai Zhong Yi Yao Za Zhi. 2001;2:4-6.

36. Shen J. The survival rate in 80 non-small cell lung cancer patients when using TCM combined with chemotherapy. World Health Digest Chinese Traditional Medicine. 2008;7:172-173.

37. Xue YB, Zhou XY, Shi HC. Clinical observation in 36 non-small cell lung cancer treating with chemotherapy and TCM. Jiangsu Zhongyiyao. 2008;40:42-44.

38. Hong Z, LX P, Chen JF, Huang FL, Zheng XL. Traditional Chinese Medicine Ai Di Parenteral solution with NP regimen for reversal of multidrug resistance in non-small cell lung cancer with P-gp overexpression. Journal of Clinical Medicine in Practice. 2005;9: $30-33$.

39. Zhang WQ, Du FM, Zhao MC, Zhao SF, Zhao YM. Buqihuoxue protocol combined with chemotherapy in advanced non-small cell lung cancer. Zhejiang Zhongxiyi Jiehe Zazhi. 2005;15:340-341.

40. Wang ZQ, Xu ZY, Zhou WD, Deng HB, Zhang M, Zhang H. Clinical research of TCM combined with western medicine in non-small cell lung cancer treatment. Traditional ChineseMedicine Journal. 2006;5:41-43.

41. Shen DM, Xu F. Clinical observation of combined Chinese and western medicine in treating non-small cell lung cancer. Shanghai Journal of Traditional Chinese Medicine. 2005;39:5-6.

42. Lu XC, Liu JL, Cui HY, Wang LQ, Wu S, Zhang QX. Clinical research of combined Chinese and western medicine in non-small cell lung cancer treatment. Modern Oncology. 2005;13:832-834.

43. Luo XL, Qing DM, Li JC, Gong HW. TCM treatment in 174 old patients with non-small cell lung cancer. Zhongliu Fangzhi Yanjiu. 2004;31:657-658.

44. Wang JX, CL Zhu. A clinical observation of the effect of supplementing Qi and nourishing yin prescription combined with MOP on the stage III IV of the nonsmall cell lung cancer. Shi Yong Zhong Xi Yi Jie He Za Zhi. 1997;10:1839-1840.

45. Zhou HF. Chinese herbal medicine Yi Qi Yang Yin Tang combined with vinorelbine-cisplatin chemotherapy in the treatment of 46 patients with stage III and IV non-small-cell lung cancer. Zhejiang Zhongyi Zazhi. 2003;38:474.

46. Jin CJ, Li LN, Cui Q, et al. Clinical observation of chemotherapy and Chinese Medicine in treating advanced non-small-cell lung cancer. Shanghai Zhong Yi Yao Za Zhi. 2003;37:16-17.

47. Yu LL, Han ZY. Clinical observation of Chinese herbal medicine combined with interventional chemoradiotherapy in the treatment of non-small-cell lung cancer. Zhongguo Zhongxiyi Jiehe Zazhi. 2003;23:56-57.

48. Liu SS. Clinical research of Fei Yi Liu He Ji in the treatment of primary bronchopulmonary cancer. Shan Dong Zhongyiyao Daxue Xuebue. 2004;28:99-102.

49. Zou YH, Liu XM. Effect of astragalus injection combined with chemotherapy on quality of life in patients with advanced non-small cell lung cancer [Article in Chinese]. Zhongguo Zhong Xi Yi Jie He Za Zhi. 2003;23:733-735.
50. Wang WR. Ai Di injection combined with NP in the treatment of advanced non-small cell lung cancer. Jiangxi Zhongyiyao Daxue Xuebao. 2008;10:125-126.

51. Yang QR, Chen WZ, Huang JD, Chen XL. Ai Di injection combined with chemotherapy in the treatment of middle to late-stage of lung cancer. Guangming Zhongyi. 2008;23:1760-1761.

52. Lin HS, Li DR. Phase II clinical trial for evaluating the adjuvant chemotherapy for non-small cell lung cancer with Shen-Dan capsule and related Traditional Chinese Medicine. Chinese Journal of New Drugs. 2007;16:1791-1795.

53. Zhou Q. Clinical observation of treating 30 lung cancer patients with Fuzhenbuxu Decoction. Henan Zhongyi. 2009;29:369-370.

54. Li CJ, Liu JX, Liu LS, Sun JL, Li HG. Regulatory effect of jianpiwenshen recipein combining with chemotherapy on the blood level of es-tradiol in patients with lung cancer. Zhongguo Zhong Xi Yi Jie He Za Zhi. 2009;29:26-29.

55. Zhang HT, Fang ST, Huang ZY, Liu LW. Clinical observation in treating non-small cell lung cancer with chemotherapy and Jianpiyangyin and Huataiquyu Decoction. Hubei Zhongyi Zazhi. 2008; 30:11-12.

56. Li DF, Zhang H, Zhou M. Clinical study of treating middle to late stage non-small cell lung cancer using chemotherapy combined with Jianpiyishen Decoction. Journal of Sichuan of Traditional Chinese Medicine. 2008;26:51-53.

57. Xu L, Li AY, Wang JX. FACT-L clinical research of Keliuwan combined with TP in advanced non-small cell lung cancer treatment Jilin Zhongyiyao. 2008;28:794-796.

58. Chen GY, Cui L, Liu JJ. Clinical study of treating middle to late stage of non-small cell lung cancer with chemotherapy and Yiqiyangyin Decoction. Jiangsu Zhongyiyao. 2007;39:34-35.

59. Liu LS, Liu JX, Li CJ, Tian JH, Shi ZM. Clinical Effect of YiqiYangyin Jiedu Decoction in Treating Patients with Advanced Non-small Cell Lung Cancer. Zhongguo Zhong Xi Yi Jie He Za Zhi. 2008; 28:352-355

60. Xu YQ, Ding R, Zhang Y, Luo Y, Xu JW. Clinical observation in nonsmall cell treatment with TCM and chemotherapy. Liaoning Zhongyi Zazhi. 2007;34:916-917.

61. Li L, Qing YK, J G, Liu Q, Zhang ZW. Chemotherapy using NP combined with TCM in the treatment of 44 patients with advanced nonsmall - cell lung cancer. Zhongguo Zhongxiyi Jiehe Waike Zazhi. 2005; 11:489-490.

62. Luo SZ, Long JH, Yu XY. The clinical observation of advanced non-small cell lung cancer treated with Shenqifuzhen injections combined with PTX and DDP. Cancer Research and Clinic. 2006; 18:181-183.

63. Feng L, Hua JB, Piao BK. Clinical Study of Feiliuping on Quality of Life of Lung Cancer Patients. Chinese Journal of Information on TCM. 2006;13:12-13.

64. Yang C, Wang RP. Clinical observation of Keliuwan in advanced non-small cell lung cancer treatment. Chinese Archives of Traditional Chinese Medicine. 2004;22:2090-2091.

65. Li M. Clinical observation of Yiqihuatan methods in non-small cell lung cancer treatment. Journal of Hebei TCM and Pharmacology. 2007;22:12-14.

66. Kong YZ, Sun Y, Len JX, Yang QL. Zhenqifuzhen capsule combined with chemotherapy in non-small cell lung cancer treatment. Jiaoning Zhongyi Zazhi. 2005;32:872-873.

67. Wen HY, Wang XS, Chen MX. A randomised controled study of combined Chinese and western medicine in treating non-small cell lung cancer. Liaoning Zhongyi Zazhi. 2007;34:75-76.

68. Xie Y, He WG. TCM Jianji II combined with NP chemotherapy in advanced non-small cell lung cancer treatment. Cancer Research and Clinic. 2006;18:701-703.

69. Liu F. Clinical Observation to Non-small cellular lung cancer treated with fuzheng guben decoction and chemotherapy. Zhejiang Zhongyiyao Daxue Xиеbao. 2007;31:316-318. 
70. Lu YX, Bai GD, Huang DP, Qin B, Liu M. Zhongyao Zengmian Decoction combined with chemotherapy in the treatment of advanced non-small cell lung cancer. 2008;31:12-14.

71. Wang C, Wang LM, Xie GR. Clinical observation of Aidi injectable liquid simultaneously used with chemotherapy to treat non-small-cell lung cancer. Tianjin Zhongyi. 2002;19:61.

72. Gao P. Clinical observation of Ai Di Zhu She Ye combined with chemotherapy in treating late stage non-small cell lung cancer. Henan Zhongyi. 2003;10:45-46.

73. Zhang NS, Yang DZ, Niu RG, et al. Analysis of 98 cases of middle and late stage non-small-cell lung cancer treated with Ai Di Zhu She Ye combined with chemotherapy. Zhongyiyao Xuekan. 2003; 21:1599.

74. Lu J, Lu L, Fang J. Analysis of 75 patients with late stage non-small-cell lung cancer treated with Ai Di Zhu She Ye and chemotherapy. Shiyong Zhongyi Neike Zazhi. 2003;17:136.

75. Cheng WC, Ma L, Jin C, et al. Observation of the effects of Ai Di Zhu She Ye combined with Irinotecan protocol in the treatment of middle and late stage non-small-cell lung cancer. Zhongliu Yanjiu Yu Linchuang. 2003;15:199-200.

76. Zhang LH, Wang FZ, Liu GR. Observation of the effect of Chinese herbal medicine Ai Di Zhu She Ye combined with chemotherapy on short-term quality of life in late stage nonsmall cell lung cancer. Zhongguo Shiyong Neike Zazhi. 2003;23:427-428.

77. Wang DJ, Chen YL, Ren J, et al. A randomized clinical study on the efficacy of Aidi injection combined with chemotherapy in the treatment of advanced nonsmall cell lung cancer. Zhongguo Feiai Zazhi. 2004;7:247-249.

78. Li TS. Clinical study of Fei Bao Dan combined with chemotherapy in the treatment of advanced non-small-cell lung cancer. Zhongguo Zhongyiyao Xinxi Zazhi. 1999;6:50.

79. Liu Q. Observations of effectiveness of Yi Qi San Jie Fang combined with chemotherapy in treating 35 cases of middle and late state nonsmall-lung cancer. Shanxi Zhongyi. 1999;15:26-27.

80. Chu GT, Cao YS, Zheng AP. 64 cases of non-small-cell lung cancer treated with Fu Zheng Qu Yu Tang combined with chemoradiotherapy. He Nan Zhongyiyao Xuekan. 1999;14:31-32.

81. Li DY, Ou CM, Li GD, et al. Clinical observations of Fu Zheng Pai Du Kang Ai Fang in increasing effectiveness and reducing toxicity of chemotherapy in non-small-cell lung cancer. Zhongguo Zhongxiyi Jiehe Zazhi. 2000;20:208-209.

82. Sun SX, Wang XM, Yu RC. Analysis of Chinese medicine to benefit qi and tonify blood in the treatment of late-stage non-small-cell lung cancer. Zhongguo Zhongyiyao Xinxi Zazhi. 2002;9:57-58.

83. Wang ZL. Clinical observation of Yi Qi Yang Yin Gu Ben Tang to reduce side effects of chemotherapy in patients with non-small-cell lung cancer. Jiangxi Zhongyiyao. 2002;33:40.

84. Zhou H, Zhang DC. Zhang Shi Kang Ai San No. 5 combined with chemotherapy the treatment of late stage lung cancer. Hubei Zhongyi Zazhi. 2003;25:27-28.

85. Fan YF, Xu QP, Jiang N, et al. Clinical study of tumor response with integrated Chinese Western medicine in the treatment of non-small-cell lung cancer. Fujian Zhongyiyao. 2003;34:6-7.
86. Cao Y, Yuan SH, Qiao ZB, et al. Clinical research on Yi Qi Yang Yin Fang combined with chemotherapy in the treatment of late stage nonsmall-cell lung cancer. Zhongguo Zhongyi Jichu Yixue Zazhi. 2003; 9:32-33, 595.

87. Jia YJ, Shi FM, Jia CS, et al. Clinical research of Xiao Yan Tang in the treatment of late stage non-small-cell lung cancer. Tianjin Zhongyiyao. 2004;21:108-110.

88. Liu JX, Pan MQ, Li YH, et al. Clinical study of Jin Fu Kang oral liquid for treating non-small-cell lung cancer. Zhongliu. 2001;21:463-465.

89. Gao CR, Xia HP, Shi JG, et al. Clinical observation of Shenqi pills combined with chemotherapy to treat non-small-cell lung cancer. Zhongguo Zhongxiyi Jiehe Zazhi. 2001;21:908.

90. Fei CB, Wang YM, Wang LL, et al. Fu Zheng Chinese medicine combined with chemotherapy in the treatment of non-small-cell lung cancer. Liaoning Zhongyi Zazhi. 2003;30:266-267.

91. Zhang XH, Li J, Sun CY, et al. Clinical research on Ai Di Zhu She Ye combined with chemotherapy in the treatment of middle and late stage non-small-cell lung cancer. Zhonghua Zhongxiyi Zazhi. 2004; 5:230-231

92. Mao CH. Effects of chemotherapy and TCM on immune function and quality of life of patients after the operation of lung cancer at nonage. Guiding Journal of TCM. 2007;13:16-17.

93. Tian JH, Liu LS, CJ L, Shi ZM. Effects of fuzheng jiedu decoction on quality of life of patients with non-small cell lung cancer. ACTA Universitatis Traditionis Medicalis Sinensis Pharmacologiaeque Shanghai. 2007;21:34-37.

94. Zhong Y, Zhou RY, Wu LY, Wang YP, Lin HY. Study of clinical effect of feiyi decoction in treating NSCL of elderly patients combined with chemothreapy. Liaoning Zhongyi Zazhi. 2008;38:1722-1724.

95. Vickers A, Goyal N, Harland R, Rees R. Do certain countries produce only positive results? A systematic review of controlled trials. Control Clin Trials. 1998;19:159-166.

96. Wu T, Li Y, Bian Z, Liu G, Moher D. Randomized trials published in some Chinese journals: how many are randomized? Trials. 2009;10:46.

97. Yu GP, Gao SW. Quality of clinical trials of Chinese herbal drugs, a review of 314 published papers [Article in Chinese]. Zhongguo Zhong Xi Yi Jie He Za Zhi. 1994;14:50-52.

98. Schulz KF, Chalmers I, Grimes DA, Altman DG. Assessing the quality of randomization from reports of controlled trials published in obstetrics and gynecology journals. JAMA. 1994;272:125-128.

99. Schulz KF, Chalmers I, Hayes RJ, Altman DG. Empirical evidence of bias. Dimensions of methodological quality associated with estimates of treatment effects in controlled trials. JAMA. 1995;273:408-412.

100. Balk EM, Bonis PA, Moskowitz H, et al. Correlation of quality measures with estimates of treatment effect in meta-analyses of randomized controlled trials. JAMA. 2002;287:2973-2982.

101. Pittler MH, Ernst E. Artemether for severe malaria: a meta-analysis of randomized clinical trials. Clin Infect Dis. 1999;28:597-601.

102. Matheson NJ, Harnden AR, Perera R, Sheikh A, SymmondsAbrahams M. Neuraminidase inhibitors for preventing and treating influenza in children. Cochrane Database Syst Rev. 2007: CD002744.
Lung Cancer: Targets and Therapy

\section{Publish your work in this journal}

Lung Cancer: Targets and Therapy is an international, peer-reviewed, open access journal focusing on lung cancer research, identification of therapeutic targets and the optimal use of preventative and integrated treatment interventions to achieve improved outcomes, enhanced survival and quality of life for the cancer patient. Specific topics covered in the journal include:

\section{Dovepress}

Epidemiology, detection and screening; Cellular research and biomarkers; Identification of biotargets and agents with novel mechanisms of action; Optimal clinical use of existing anticancer agents, including combination therapies; Radiation and surgery; Palliative care; Patient adherence, quality of life, satisfaction; Health economic evaluations. 